\title{
Partial Discharge Part XVIII: Errors in the Location of Partial Discharges in High Voltage Solid Dielectric Cables
}

\author{
F.H. Kreuger, M.G. Wezelenburg, A.G. Wiemer, and W.A. Sonneveld \\ Technical University Delft
}

\section{Introduction}

$\mathbf{P}$ artial discharge within the dielectric of solid dielectric cable greatly shortens the cable life. As a result, all solid dielectric cable is tested for partial discharge (PD) after the manufacturing process [1]. Location of partial discharge sources during the testing process is of economic value as it allows "good" sections of the cable to be salvaged. This article reviews the phenomena and practical considerations which limit the accuracy of PD location in solid dielectric cable to about $\pm 0.4 \%$ of the length tested.

\section{History}

The location of PD in solid dielectric cable through measurements of traveling wave electromagnetic phenomena was introduced by the first author in 1961 [2] and has become the standard method for PD location in such cables. Over the years, many studies have been directed toward improved PD location accuracy and better sensitivity [2-9], while other studies have applied traveling wave measurements to the testing of cables as short as $20 \mathrm{~m}$ and to $\mathrm{SF}_{6}$ gas insulated switchgear of some tens of metres in length [10-12]. Most of these studies give an indication of PD location accuracy, usually by presenting the location error at one arbitrary site, but no overall analysis of PD location accuracy has been presented. This article surveys the various sources of error as demonstrated through systematic experiments.

\section{Detection Topology}

The location of a PD source through the measurement of traveling wave phenomena can be based on measurements from one or both ends of the cable [2]. In the former case, a single-input instrument is employed to receive a first pulse which propagates directly from the PD location to the end of the cable while a
All solid dielectric high voltage power cable is tested for partial discharge. Location of any $P D$ present facilitates salvage of the remaining cable. Accurate location of PD in solid dielectric cable therefore has significant economic impact.

second, later, pulse is received as a result of a reflection off the far end of the cable. This is the configuration most commonly used. In the latter case, the PD-induced pulse is detected at each end of the cable. In both cases, the time between pulses indicates the PD location, and in each case, the system can be calibrated by injecting a pulse at one end of the cable to determine the total propagation time of the cable under test. The measured times between pulses are then interpreted relative to this experimentally determined propagation time. Through such calibration, the PD location can be expressed as a fraction of the total cable length.

\section{PD Pulse Properties}

The properties of PD pulses have been reviewed in previous papers in this series [13-15]. Briefly, a partial discharge (PD) pulse in an unaged dielectric gives rise to an electromagnetic pulse with a risetime in the ns range and a pulse width (FWHM) in the range of $1.5 \mathrm{~ns}$. The optimum bandwidth for detection of such a "fast" pulse is in the range of $300 \mathrm{MHz}$ [14,16]. Discharge from electrical trees in aged solid dielectrics often takes the form of a cascade of such fast pulses. In aged cavities, the PD pulse can broaden to have a risetime of up to several $10^{\prime} \mathrm{s}$ of ns and a pulse width up to some hundreds of ns [17]. For such a broad pulse, a bandwidth in the range of $10 \mathrm{MHz}$ is sufficient.

0883-7554/93/\$1.00@1993 


\section{Attenuation Characteristics of Solid Dielectric Cables}

Solid dielectric power cable generally has a large conductor surface area and a low loss dielectric. Thus one might expect very low losses at high frequencies. However, solid dielectric power cable incorporates semiconductive layers to reduce stress enhancements at the conductor-dielectric interface. High frequency losses are caused by the propagation of radial displacement current through the resistance of these layers $[18,19]$. Obviously the displacement current increases with frequency, so that while this source of attenuation is insignificant at power frequency, it becomes the dominant loss mechanism at frequencies relevant to PD pulse propagation. The losses caused by the semiconductive shields depend on the dielectric constant and resistivity of the semiconductive layers, and these properties tend to be frequency-dependent. The properties of the semiconductive materials employed in solid dielectric cable are restricted by standards to assure their effectiveness as conductors, i.e., only a minimum conductivity is specified. Thus the frequency-dependent attenuation of solid dielectric cables can vary widely. As will be shown below, this translates into an error in PD location.

\section{Optimum PD Detection Bandwidth}

The frequency-dependent attenuation of power cable complicates PD location in several respects. The ability to detect a signal in noise is determined by the amount of information known about the signal. If the signal bandwidth is known, then a detection bandwidth should be selected which maximizes the signalto-noise ratio. The frequency-dependent attenuation of power cable implies a PD pulse bandwidth which depends on the length of cable through which the pulse has propagated. If a wide detection bandwidth is employed, unaged sources close to the detection end of the cable will be measured with high sensitivity; however, sensitivity is compromised for PD pulses which are generated further from away. Also, the shape of measured pulses will be highly sensitive to PD source location. For an unaged source close to the measurement end of the cable, the first pulse will be very sharp while the PD pulse which propagates down to the far end of the cable and reflects will be much broader by the time it reaches the detector. This can cause a substantial error in PD location, which is based on the time difference between the two pulses as this time difference will, in part, reflect the difference in risetime or time to peak of the second pulse. If a relatively narrow detection bandwidth is selected, the detection bandwidth can determine the pulse shape and thereby reduce this source of error; however, the ability to locate a pulse in time is determined by the "sharpness" and signal-to-noise ra- tio the pulse. A narrow detection bandwidth limits pulse "sharpness" and thereby limits PD location accuracy. Obviously a detection bandwidth must be selected which represents a good compromise given typical cable frequency-dependent attenuation characteristics and typical test lengths. Past studies based on the measured high frequency attenuation of solid dielectric cable [16] have demonstrated that a bandwidth in the range of 10 to $20 \mathrm{MHz}$ represents a reasonable compromise. This choice is further justified by the increase in PD pulse risetime and pulse width with aging which is often observed after some 10 to 20 minutes of testing [17]. A PD detection band width of about $10 \mathrm{MHz}$ is near optimum for such longer pulses.

In summary, the bandwidth of about $10 \mathrm{MHz}$ typically employed in cable PD location systems has a sound basis. This is one of the reasons that commercially available cable PD locating instruments are designed with this bandwidth.

\section{Sources of Error}

Error in PD location is caused by both mechanical and electrical phenomena. Electrical phenomena include:

1. Pulse distortion caused by frequency-dependent propagation characteristics of a solid dielectric power cable.

2. Time base errors.

3. Interfering noise in the form of circuit noise or quantization noise in digital systems.

Mechanical sources of error include:

1. Inaccurate knowledge of cable length caused by measurement errors in the metering wheel used during manufacture, buckling of the cable, changes in temperature, etc. as well as length measurement errors during the PD location process; such trivial sources of error can be reduced through incorporation of a marking tape within the cable or metering marks on the exterior of the cable.

2. Errors caused by failure to account for the lengths of cable removed during termination.

Mechanical errors can be quite substantial but have not been discussed in earlier publications. Both sources of error, electrical and mechanical, are discussed in detail below.

\section{Electrical Sources of Error}

\section{Time base Errors}

Time base accuracy of analog oscilloscopes is generally specified as better than $0.2 \%$. In the present application, a time difference is being measured between two 


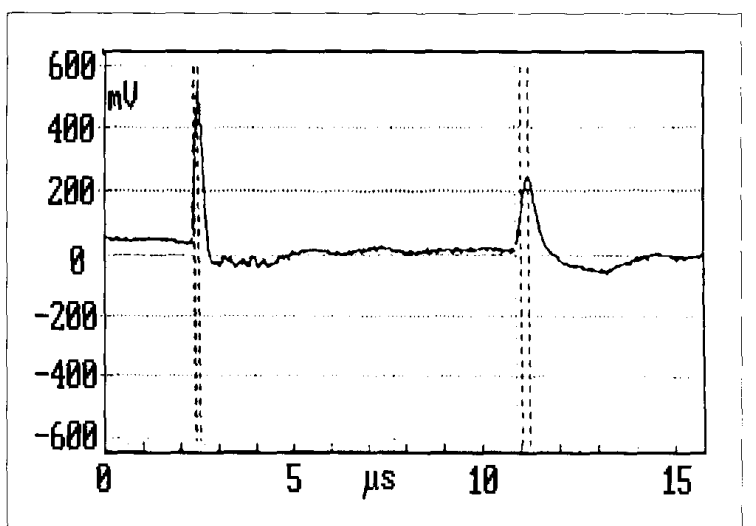

Fig. 1. Time delay and difference in distortion between direct and reflected wave based on an oscillogram recorded using a commercially available $20 \mathrm{MHz}$ detector.

pulses, and this is being compared to the total propagation time of the cable as determined during calibration with the same oscilloscope time base. Thus only a relative time delay must be determined, and the effect of time base error is greatly reduced, almost certainly to well below $0.1 \%$. When an analog oscilloscope is employed, linearity error across the screen must also be considered; however, this source of error can be reduced through use of a delayed time base, which permits measurement of all time differences at the same position on the screen. Digital oscilloscopes, which are coming to dominate commercial PD measurement, generally have a time base accuracy in the range of $0.01 \%$ with negligible nonlinearity, so that time base error becomes irrelevant.

\section{Noise and Quantization Error}

A substantial part of the scatter in time difference measurements is the result of noise and random disturbances superimposed on the signal. In an unshielded industrial measurement environment, disturbances could arise from the starting of motors, commutation in SCR-controlled power systems, etc. The effect of such scatter can be reduced through statistical analysis of a large number of samples. At a minimum, the time difference as determined from 20 to 50 waveforms can be averaged. Such averaging can reduce, but not eliminate, scatter in the measured location, as will be demonstrated below using experimentally measured data.

Quantization error caused by digitizing of signals can be separated into error in the time at which the signal is digitized and error in quantization of the signal. The effect of these errors is minimized by using a high sampling frequency, high resolution digitizer with a bandwidth consistent with an overall system bandwidth in the range of $10 \mathrm{MHz}$.

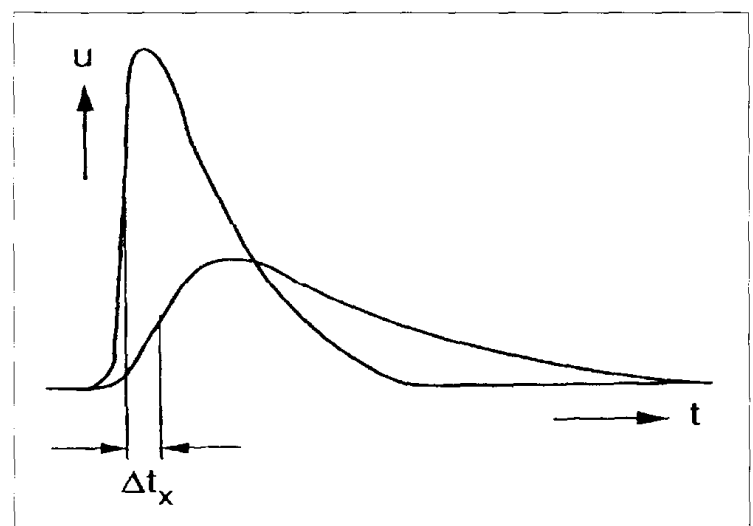

Fig. 2. Initial PD pulse and pulse as distorted by traveling a distance " $x$ " through the cable, which causes an error $\Delta t_{x}$ in the measured propagation time.

\section{PD Pulse Distortion}

The phenomena which cause distortion of a PD pulse propagating down a solid dielectric power cable have been discussed in some detail above. As the two pulses travel unequal lengths of cable, the shapes of the direct and reflected waves will differ, as seen in Fig. 1. With increasing distance propagated, the peak of the pulse lags further and further behind the foot of the pulse, i.e., the pulse risetime increases. This raises the question of the point on the pulses between which the time should be measured, which could be based on the peaks, $50 \%$ of the rise, or on the foot. This question will be addressed below through experimentally measured data.

Pulse distortion causes an error in the measured time difference as demonstrated in Fig. 2. After a difference in propagation distance of " $x$ ", the time difference between the pulses is measured to be $\Delta t_{x}$ too large. This means that the observed calibration time $t^{\prime}$ cal for a pulse which propagates the full length of the cable and back is seen as

$$
t_{c a l}^{\prime}=\frac{2 l}{v}+\Delta t_{2 l}
$$

where $l$ is the length of the cable, $v$ is the propagation velocity without distortion, and $\Delta t 2 l$ is the error in time difference after propagating $2 l$.

The first order approximation for such an effect would be that the attenuation-induced pulse delay is proportional to the distance propagated. However, such an effect simply reduces the apparent pulse propagation velocity. Since PD location is determined through relative timing measurements, such a propagation distance-dependent delay has no effect on PD location accuracy.

The effect of pulse distortion is complex for several reasons including: 
1. Distortion of the PD pulse occurs as a result of the frequency-dependent attenuation in the cable but also as a result of the frequency-dependent reflection coefficient at the "far" termination. These two effects cannot be separated on the basis of a measurement made from one end. During PD location, one PD-induced pulse is distorted only as a result of propagation through the cable, while the other pulse is distorted as a result of propagation through the cable and as a result of reflection. Over the relevant frequency range, frequency-dependance of the reflection coefficient can be made negligible under laboratory test conditions.

2. Power cable attenuation is a strong function of frequency. The very high frequency content of the pulse is lost very quickly, while lower frequency content is more stable. As a result, the risetime of a "fast" PD pulse will degrade very rapidly over the first few 10 's of metres and increasingly slowly thereafter. The initial attenuation has no effect on the measured time difference as a result of the limited $(10 \mathrm{MHz})$ measurement bandwidth. Only when as the pulse bandwidth degrades appreciably below $10 \mathrm{MHz}$ does pulse distortion begin to degrade the time difference measurement. The degree of such degradation depends on the cable length and attenuation characteristics.

3. PD pulse shapes differ, and several PD pulse shapes can be generated simultaneously from the same defect. Distortion of "slow" pulses, as may be generated after aging [17], is much less than distortion of "fast" pulses; thus the location error may depend on the unknown, and to a large degree unknowable, nature of the initial PD pulse.

Given that a $10 \mathrm{MHz}$ system bandwidth limits pulse risetime to greater than $35 \mathrm{~ns}$ and given that pulse attenuation and reflection-induced distortion increase the risetime from this value, small differences in waveshape result in relatively large differences in time measurement. This leads to large scatter in PD location and systematic errors which depend on PD location, as will be shown below through experimental data.

\section{Mechanical Errors}

The primary mechanical error is uncertainty in the length of the cable. During manufacture, cable length is usually measured with a metering wheel or caterpillar, and the measured length observed during the last stage of manufacture is recorded. The usual metering wheel has an error of about $0.2 \%$ when in good working order. This error can increase to the range of $1 \%$ if the wheel is contaminated or worn. Contactless metering systems have claimed accuracies in the range of $0.1 \%$. Practical location accuracy is also jeopardized by differences in temperature, buckling of the cable, elasticity of cabled conductors, etc. These issues are discussed further in an appendix.

Care must be taken not to make trivial errors in determining the effective cable length as tested. Such errors can arise from failing to account for ground shield which is removed to install test terminations.

Mechanical accuracy is generally much improved if a cable is provided with an internal meter band or with external meter marks. Both the cable length and PD location are then deduced relative to these marks, so that far fewer errors are introduced through mechanical uncertainties.

\section{Experimental Results}

Experiments to determine typical PD location error have been carried out using a detector with a $10 \mathrm{MHz}$ bandwidth. As described above, this bandwidth represents a reasonable compromise among many factors which affect PD location accuracy and is typical of many commercial PD location systems designed for solid dielectric cable. Tests were carried out using three methods to determine time differences:

1. Peak detection. The highest point in Fig. 2 is taken to mark the time of occurrence. Spurious peaks caused by high frequency noise are rejected if they occur within $150 \mathrm{~ns}$ of this peak.

2. $50 \%$ detection. The pulse arrival time is taken to be at the point where the pulse front reaches $50 \%$ of its peak amplitude.

3. Threshold detection. A base-level is determined (which may differ slightly from the zero level of the detector as shown in Fig. 3). The pulse time is defined through extrapolation of the wavefront to the base level.

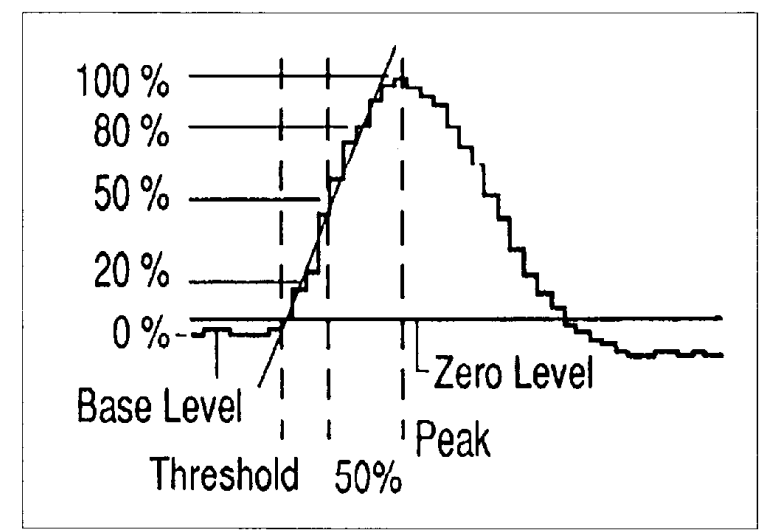

Fig. 3. Peak, $50 \%$ and threshold detection criteria. 
In each case, the time differences between 20 to 50 pulses pairs are analyzed to determine PD location. Either the mean or mode is used to calculate the PD position. Through the three criteria for pulse time difference and the two criteria for reducing the 20 to 50 time differences to a single number, six "PD locations" are determined.

Extensive tests have been carried out on a $200 \mathrm{~m}$, $15 \mathrm{kV}$ cable with metering marks on the outer sheath as well as a $590 \mathrm{~m}, 10 \mathrm{kV}$ cable without metering marks. The latter cable was divided into 5 pieces of about 100 $\mathrm{m}$ and various pieces of shorter length. By combining these lengths in various ways and injecting a discharge at an interface, many different "PD locations" could be simulated. The precise length of the unmarked cable was determined through capacitance measurement using a Schering Bridge. The length-to-capacitance ratio for each length was determined, and the length-to-capacitance ratio of one length was taken as standard. The accuracy of the Schering Bridge measurement was $0.2 \%$, and given the relative nature of the PD location process, the contribution of the length measurement error to the PD location error falls below $0.1 \%$.

\section{Blind Length}

If a PD source is near the "far" end of the cable, the observed pulses may overlap and can no longer be distinguished. This results in a "blind length" at the far end of the cable for which PD location is impossible. For the present detection system and cables tested, this blind length is on the order of $25 \mathrm{~m}$. The same blind length can occur at the "near" end if the input impedance of the detector is not matched to the characteristic impedance of the cable under test.

The blind length can be overcome by measuring twice, once from the near end of the cable which results in a measured delay time $t_{n}$, and at the same time from the far end of the cable which results in a time delay $t_{f}$. Then the discharge location is

$$
y=\frac{t_{n}}{t_{f}} L
$$

where $y$ is the distance of the discharge location from the far end and $L$ is the total length of the cable under test.

Under actual test conditions, the complication of shifting the connections is rarely undertaken, and a blind length at both ends is accepted. Experience indicates that most problems are caused by end effects in production or handling, so that removing a limited length of cable from an end is generally more cost effective than complex testing.

\section{Test Results}

A small capacitor was used as a source of natural discharges. If stressed at an overvoltage, this capacitor produced discharges of about $30 \mathrm{pC}$ with a risetime in the ns region. The cable conductor was accessible at various locations along the cable, and the capacitor was connected between the conductor and sheath at these locations to simulate a discharge in the dielectric. The effect of the added lumped capacitance was assessed and found to be negligible. The capacitor was applied to 40 different locations of the 590 metre, $10 \mathrm{kV}$ cable. The delay time was determined using the six different criteria described above. For example, Fig. 4 shows the location error as a function of position when the each pulse time delay is measured from the pulse peak and the mode to analyze the resulting data. The tests were repeated using a $5 \mathrm{pC}$ calibration pulse, and the resulting data are shown in Fig. 5 . The results of both tests were combined, and an area was indicated which covers $99 \%$ of all errors. In Figs. 6 to 11, these areas are shown for the six criteria.

The 210 metre, $15 \mathrm{kV}$ cable was tested using two of the six criteria, and the results were entered in Figs. 7 to 11. The errors for this cable were somewhat smaller, as may be expected from the reduced pulse distortion which results from a shorter length.

Analysis of the data plotted in Figs. 7 to 11 suggests a tendency toward smaller errors as the discharge location approaches the far end of the cable. This tendency was confirmed by regression analysis. In all six cases, the data proved to be Normally distributed, and the regression lines indicated an error of 2 to $3 \mathrm{~m}$ near the detector decreasing to insignificant values near the far end of the cable. This is as expected since for a PD source near the far end of the cable, both pulses travel nearly the same distance and suffer nearly the same distortion, which results in accurate relative timing independent of the initial pulse shape or frequency-dependent attenuation of the cable.

The PD location errors tend to be positive, i.e., the PD location determined from the measurements is farther from the detector than in reality. This suggests that the extra time delay caused by distortion is more than proportional to the distance travelled. The overall results of these tests are summarized in Table I. The differences in accuracy among the six algorithms are not large; however, threshold detection provides the smallest error. The choice between mode and mean remains open.

\section{Multiple Discharge Sites}

If more than one discharge site is present along the length of the cable, the test voltage and oscilloscope trigger levels can be manipulated in an attempt to sepa- 


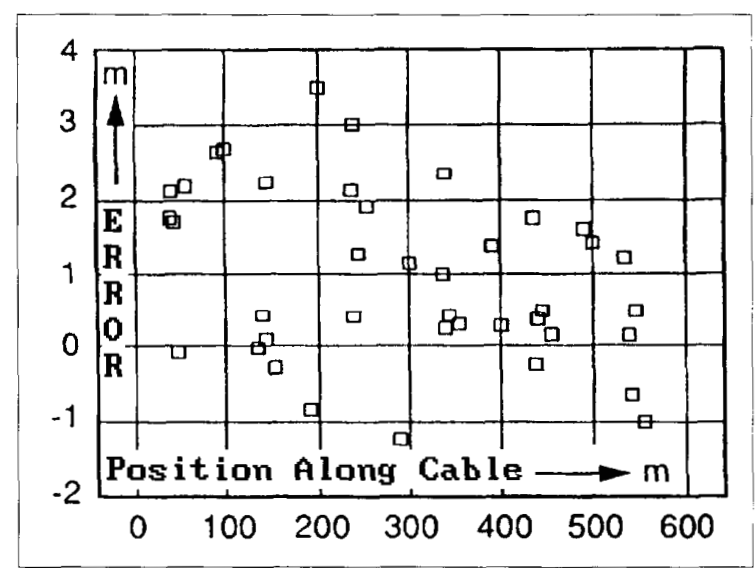

Fig. 4. Errors in discharge position as a function of position as measured with a $30 \mathrm{pC}$ discharge source. Time delay was determined using the mode of the peak.

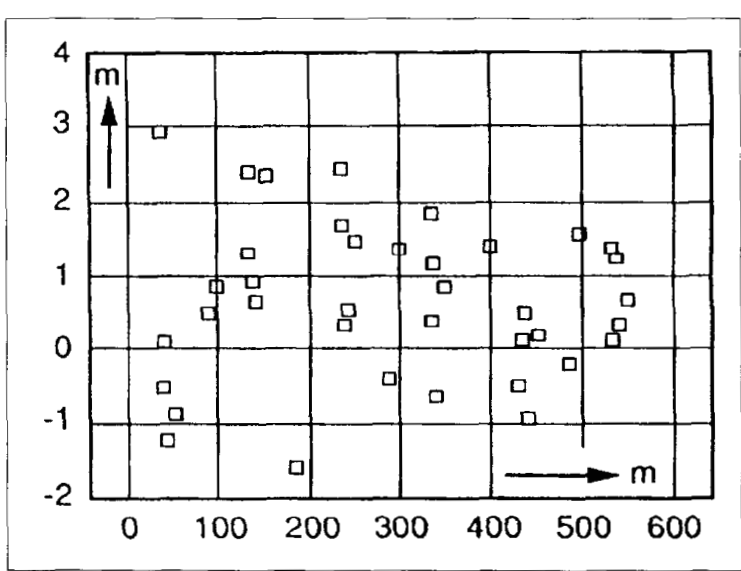

Fig. 5. Errors in discharge position as a function of PD position along the cable as measured with a $5 \mathrm{pC}$ discharge source. Time delay was determined using the mode of the peak.

rate the discharge sources. If the discharges cannot be separated in this manner, experience indicates that 2 to 3 simultaneous discharges can be distinguished. Fig. 12 shows a histogram from two simultaneous discharges in the $10 \mathrm{kV}$ cable as measured using the same detector as previously (which was developed into a commercial instrument). The histogram shows two distinct distributions with a mode at $288.5 \mathrm{~m}$ and one at $403.5 \mathrm{~m}$. No attempt has been made to automate this process further; the user must decide by eye whether one or more discharge locations are present and the degree to which multiple discharge sites can be separated. Use of the mode is preferred for data analysis as it facilitates the distinction between a large scatter of one discharge site and the apparent scatter of two discharge sites which are $10 \mathrm{~m}$ or more apart. The accuracy was also checked

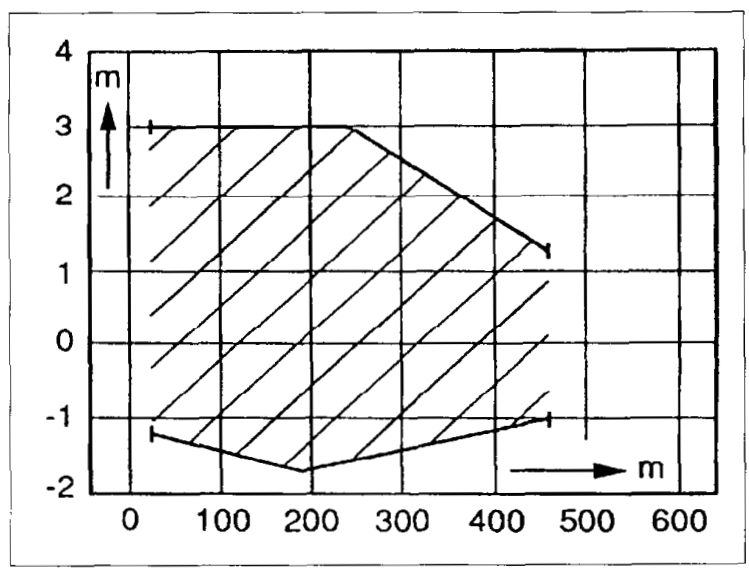

Fig. 6. Area covering $99 \%$ of all errors in PD source location measured on a $590 \mathrm{~m}, 10 \mathrm{kV}$ cable. Time delay was determined using the mode of the peak.

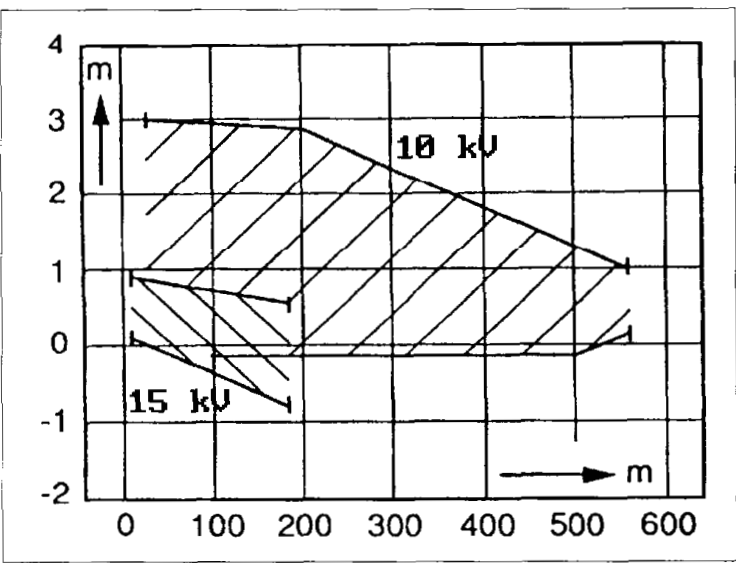

Fig. 7. Area covering $99 \%$ of all errors in PD source location measured on a $590 \mathrm{~m}, 10 \mathrm{kV}$ cable and a $210 \mathrm{~m} 15 \mathrm{kV}$ cable. Time delay was determined using the mean of the peak.

Table I

Measuring Errors vs Detection Algorithm

\begin{tabular}{|c|c|c|}
\hline & \multicolumn{2}{|c|}{ Measuring Error } \\
\cline { 2 - 3 } & At Mode & At Mean \\
\hline Peak Detection & $3 \mathrm{~m}$ & $3 \mathrm{~m}$ \\
\hline $50 \%$ Detection & $3.2 \mathrm{~m}$ & $3.5 \mathrm{~m}$ \\
\hline Threshold Detection & $2.5 \mathrm{~m}$ & $2.4 \mathrm{~m}$ \\
\hline
\end{tabular}




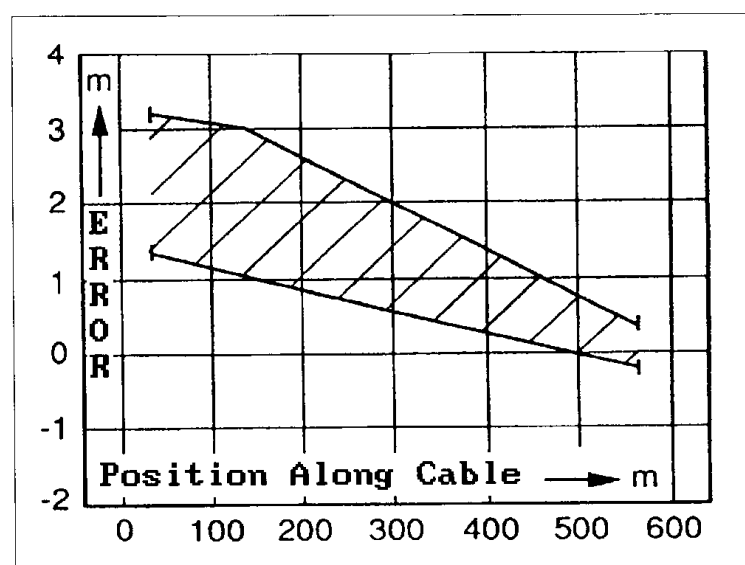

Fig. 8. Area covering 99\% of all errors in PD source location measured on a $590 \mathrm{~m}, 10 \mathrm{kV}$ cable and a $210 \mathrm{~m} 15 \mathrm{kV}$ cable Time delay was determined using the mode of the $50 \%$ amplitude.

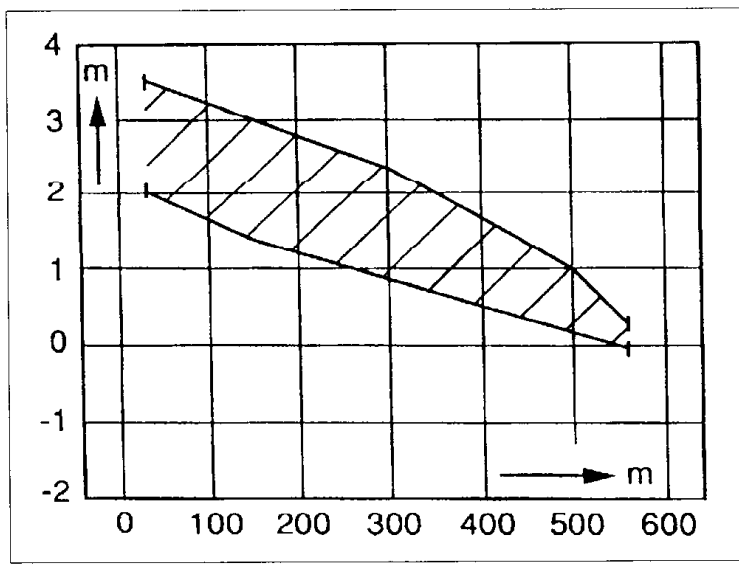

Fig. 9. Area covering 99\% of all errors in PD source location measured on a $590 \mathrm{~m}, 10 \mathrm{kV}$ cable and a $210 \mathrm{~m} 15 \mathrm{kV}$ cable. Time delay was determined using the mean of the $50 \%$ amplitude.

using $15 \mathrm{kV}$ cable under several conditions where two or three discharges were present simultaneously. PD location errors ranged between 0.1 and 0.6 metres or a maximum of $0.3 \%$ of the cable length. The $590 \mathrm{~m}, 10 \mathrm{kV}$ cable was tested with two simultaneous PD sources, which resulted in errors of 1.7 and $3.4 \mathrm{~m}$ or a maximum of $0.6 \%$ of total cable length. Apparently, location accuracy of simultaneous discharges does not differ greatly from that for a single discharge source.

\section{Sensitivity}

Although not an object of this study, the PD detection sensitivity for the two cables was determined. The traveling wave PD location circuitry used in this study is

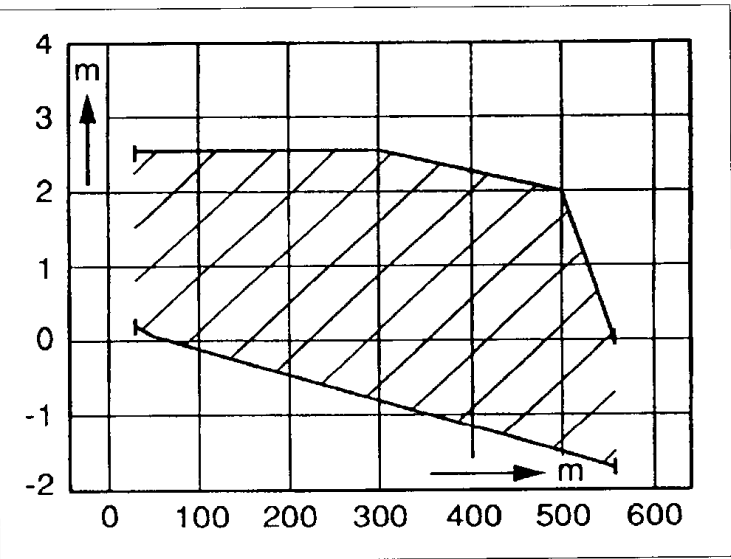

Fig. 10. Area covering $99 \%$ of all errors in PD source location measured on a $590 \mathrm{~m}, 10 \mathrm{kV}$ cable and a $210 \mathrm{~m} 15 \mathrm{kV}$ cable. Time delay was determined using the mode of the threshold.

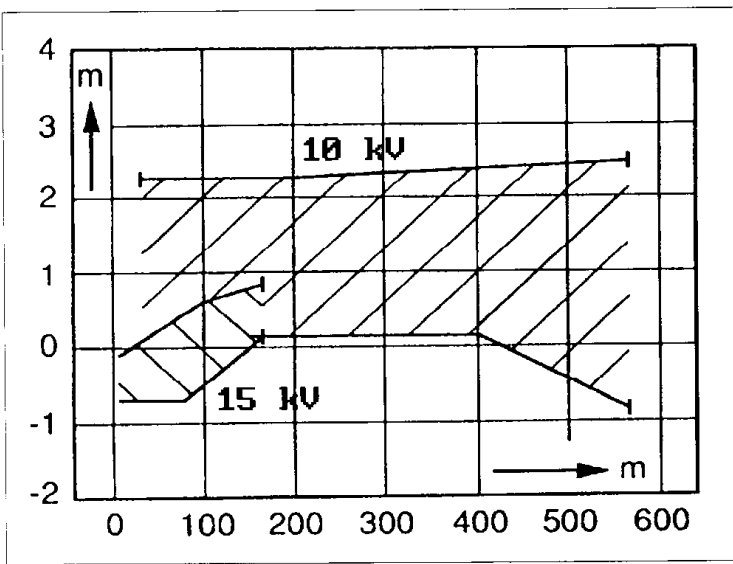

Fig. 11. Area covering $99 \%$ of all errors in PD source location measured on a $590 \mathrm{~m}, 10 \mathrm{kV}$ cable and a $210 \mathrm{~m} 15 \mathrm{kV}$ cable. Time delay was determined using the mean of the threshold.

less sensitive to ambient noise than conventional PD detectors so that tests could be performed without special precautions or additional shielding. An analysis of the sensitivity which can be achieved with this circuit is given in [3] and amounts to 0.2 to $0.5 \mathrm{pC}$ if the input circuit is well-matched to the cable. This is reasonably consistent with the calculated sensitivity.

The 590 metre cable was tested with a commercially available detector. PD sources down to $3.5 \mathrm{pC}$ could be located. The $200 \mathrm{~m}$ cable was tested with a locally built PD location circuit with which PD sources down to $2 \mathrm{PC}$ could be located. Through use of a step-up transformer at the detector input, sensitivity was improved to 0.5 pC. Both results are in reasonable agreement with [3] and with other statements in the literature. 


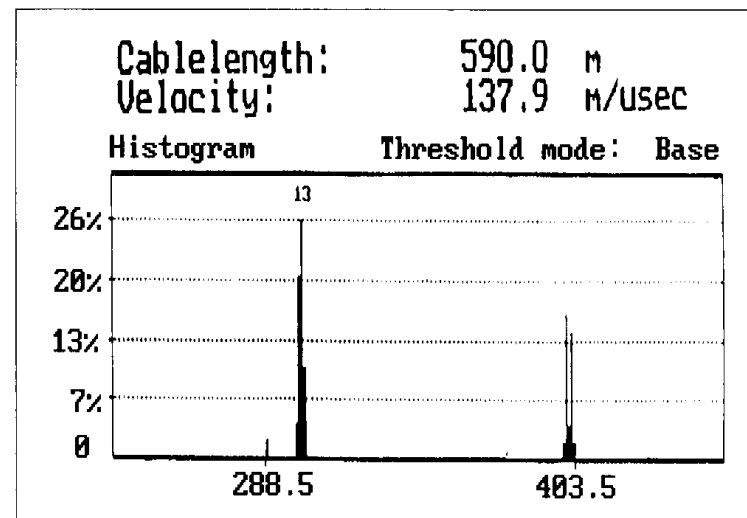

Fig. 12. PD location histogram showing time delay or PD source location ( $x$ axis) vs number of pulse pairs with a given time delay or location (y axis). The presence of two simultaneous PD sources is obvious.

\section{Conclusions}

Five sources of error relevant to PD location in long lengths of solid dielectric cable have been distinguished:

1. Errors in measuring time delays

2. Scatter caused by noise and disturbances

3. Pulse propagation distortion

4. Errors in cable length measurement

5. Trivial errors in experimental technique

Sources 1,4 , and 5 can be reduced to less than $0.1 \%$ (cumulatively). In that case, sources 2 and 3 dominate. Inaccuracies can be reduced through data analysis with a typical resulting error of $\pm 0.4 \%$ of the tested cable length when measured using a $10 \mathrm{MHz}$ bandwidth.

Errors in length can be eliminated if the cable under test is provided with a length indicating mechanism, either a marking tape or marks on the sheath. In the absence of such a mechanism, PD location accuracy may increase to over $\pm 1 \%$ as a result of uncertainties in the cable length measurement during production.

Experiments with a $590 \mathrm{~m}, 10 \mathrm{kV}$ cable indicate that a PD source can be located within $5 \mathrm{~m}$ with $99 \%$ confidence for a cable with a built-in length indicator or 15 $\mathrm{m}$ without a built-in length indicator. Two to three discharge sources can be located simultaneously with an accuracy similar to that for a single discharge source.

F.H. Kreuger is Professor of High Voltage Engineering at the University of Technology, Delft, the Netherlands and a Senior Member of the IEEE. He was one of the pioneers in the development of techniques for partial discharge detection, measurement, and analysis. He is well known for his books on the subject which are standard references in the field. In 1961, he proposed the use of travelling wave techniques for the location of PD based on his work from 1958 to 1961 at NKF Kabel B.V. in Delft. Prof. Kreuger is now within a year of retirement.

M.G. Wezelenburg and A.G. Wiemer studied with Prof. Kreuger from 1991 to 1992 and have since taken positions in Dutch industry.

W.A. Sonneveld is head of the High Voltage Laboratory at Delft University and acts as a coach to the students.

\section{References}

1. Chan, J.C., L.J. Hiivala, and J. Wasik "Partial Discharge - Part VIII: PD Testing of Solid Dielectric Cable". IEEE Electrical Insulation Magazine, 7, September/October 1992. p. 9. 2. Kreuger, F.H. Detection and Location of Discharges. Ph.D. Thesis, Technical University of Delft, 1961. Chapter 6.

3. Kreuger, F.H. Discharge Detection in High Voltage Equipment. Temple Press, London, 1967. or Butterworth, London, 1989. Chapter 7.

4. Macinlay, R.R. and G. Peters. "New Methods of Partial Discharge Detection and Location". Fifth International Conference on Dielectric Materials, IEE Conference Publication No. 289, June 1988. p. 175.

5. Mashikian, M.S., R. Bansal, and R.B. Northrop. "Location of Discharge Sites in Power Cables". IEEE Trans. PD-5, No. 2. April 1990. p. 833 .

6. Osvath, P. von, G. Biasutti, and W.S. Zaengl. "Zur ordung und beurteilung von teilentladungen an kunststoffhochspannungskabeln". Elektrizitatswirtschaft, 26, 1987. p 1139. 7. Wieringa, L. "Location of Small Discharges in Plastic Insulated High Voltage Cables". IEEE Trans. PAS-101, No. 7. Jan. 1985. p. 2. 8. Beyer, M. "A New Method for Detection and Location of Distributed Partial Discharges in High Voltage Cables". IEEE Trans PAS-101, No. 9. Sept. 1982. p. 3431.

9. Wolzak, P.M. "Detection of Electromagnetic Waves from Discharges within Switchgear". Fourth International Symposium on High Voltage Engineering (ISH), Athens, 1983. p. 63 10. Reeves, J.H. "The Location of Partial Discharge Sites in High Voltage Switchgear and Short Cables by a Travelling Wave Method". CIRED 1981, paper 4.12

11. Reeves, J.H. "Noninvasive Detection, Location, and Monitoring of Discharges in High Voltage Plant". International Conference on Revitalizing Transmission and Distribution, IEE Conference Publication 273 , p. 83.

12. Brown, P.M. "Detection of Electromagnetic Waves from Discharges within Switchgear". Fifth International Symposium on High Voltage Engineering (ISH) Braunschweig, 1987. paper 33.15. 13. Boggs, S.A. "Partial Discharge - Part I: Overview and Signal Generation". IEEE Electrical Insulation Magazine, 6, No. 4, July/August 1990, p. 33.

14. Boggs, S.A. "Partial Discharge - Part II: Detection Sensitivity". IEEE Electrical Insulation Magazine, 6, No. 5, September/October 1990. p. 35

15. Boggs, S.A. "Partial Discharge - Part III: Cavity-Induced PD in Solid Dielectrics". IEEE Electrical Insulation Magazine, 6, No. 6, November/December 1990. p. 11.

16. Boggs, S.A and G.C. Stone. "Fundamental Limitations to the Measurement of Corona and Partial Discharge". IEEE Trans. EI-17, April, 1982. p. 143. 
17. Morshvis, P. Partial Discharge Mechanism Leading to Breakdowm in Polymers. Ph.D. Thesis, Delft University, 1993.

18. Stone, G.C. and S.A. Boggs. "Propagation of Partial Discharge

Pulses in Shielded Power Cable". 1982 Annual Report of the Conference on Electrical Insulation and Dielectric Phenomena National Academy of Sciences, Washington, DC. p. 275 19. Boggs, S.A., J.M. Braun, and G.C. Stone, "Attenuating Voltage Surges in Power Cable by Modifying the Semiconductive Shields". Proceedings of the 1992 IEEE International Symposium on Electrical Insulation. IEEE Publication 92CH3150-0. p. 491. 20. Wainstein (or Vainstein), L.A. and V.D. Zubakov. Extraction of Signals from Noise. Prentice-Hall, 1962. Reprinted by Dover Publications.

\section{Appendix}

\section{Sources of Error in Length Measurement}

When measuring length during production and at the PD test location, the following sources of error can occur. Some of these errors are specific to metering wheels and caterpillars, while others can also occur for contactless measuring systems.

1. Skidding of a metering wheel at the surface of the cable tends to occur most often during starting and stopping of cable motion and when the cable moves up and down in the machine. Through proper machine control, such motion can be prevented.

2. Wear and/or contamination of a metering wheel can result in a change of diameter which causes a proportional error in measured length.

3. Uneven cable surface can result in the length along the cable surface being greater than the length of cable. Uneveness can be caused by diameter variations or by buckling of the cable. If the amplitude is $a$ and the wavelength is $l$, the error in length is

$\frac{\Delta l}{l}=\left[1+\frac{16 a^{2}}{l^{2}}\right]^{1 / 2}-1$

For $a / l=0.01, \Delta l / l=0.08 \%$ while for $a / l=0.03, \Delta l / l=$ $0.7 \%$.

4. The contact length of a metering wheel on a cable surface is not infinitesimal, as the wheel presses into the cable. This causes errors of the following magnitude.

5. The cable may be traveling at an angle $\alpha$ relative to the measuring instrument, which results in an error $e=\left[\frac{1}{\cos (\alpha)}-1\right]$

For an angle of $2^{\circ}$, this error amounts to $0.06 \%$.
6. Elasticity of the cable can cause substantial error which result from the natural elasticity of material in the cable and also from length variation of the cabled conductor. A short cabling pitch can result in substantial cable elasticity.

The overall inaccuracy which results from the above sources of error is difficult to estimate. A number of tests in various cable industry facilities indicates that

\begin{tabular}{|c|c|c|}
\hline $\begin{array}{c}\text { Length over } \\
\text { which wheel } \\
\text { contacts cable }\end{array}$ & Error for Wheel Diameter of \\
\cline { 2 - 3 } & $\mathbf{0 . 5} \mathrm{m}$ & $\mathbf{1 ~ m}$ \\
\hline $1 \mathrm{~cm}$ & $0.07 \%$ & $0.02 \%$ \\
\hline $2 \mathrm{~cm}$ & $0.25 \%$ & $0.07 \%$ \\
\hline
\end{tabular}

the overall error in length measurement falls well within $0.02 \%$; however, a few cases of errors as large as $1 \%$ have been recorded.

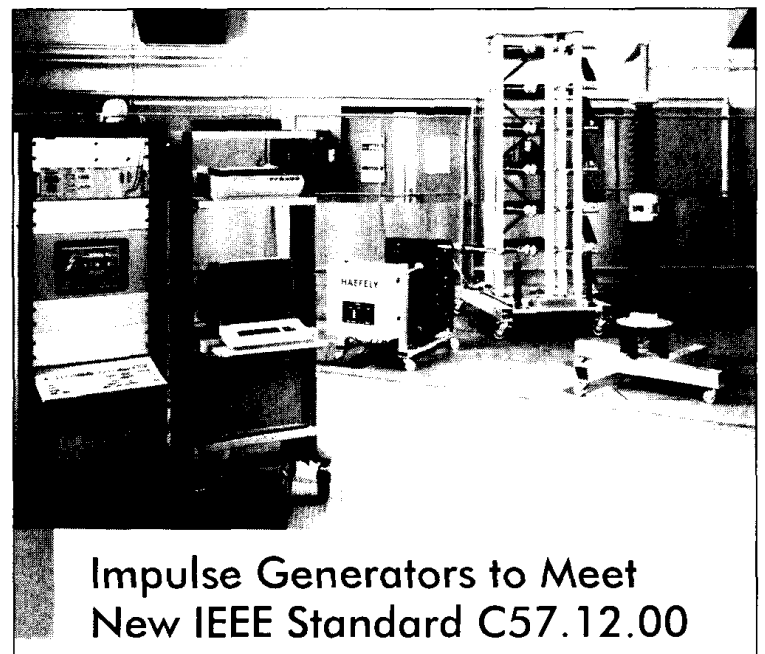

Routine impulse testing on distribution transformers is now a requirement!

HAEFELY INC.

TEST SYSTEMS DIVISION WOODBRIDGE, VA USA PHONE (703) 494.1900 FAX (703) 494-4597 HAEFELY HIGH VOLTAGE TECHNOLOGY

Reader Service Number 4 


\section{Errata}

Several errors occurred in the publication of the feature article, "Insulation Systems and Monitoring for Stator Windings of Large Rotating Machines," by W. McDermid in the July/August 1993 issue of Electrical Insulation (Vol. 9, No. 4). The corrections follow, along with the reproduction of two figures that were not fully represented in the earlier publication. Page numbers in the corrections refer to the July/August publication.

Page 7: Last sentence in the third paragraph should read: "Some of these systems are suitable for use at copper temperatures of $\pm 155^{\circ} \mathrm{C} . "$

Left column, six lines from the bottom of the page, "It is proposed to discuss here:" should be a separate paragraph, not a bulleted item.

Page 9: All four references to the term, "dielectric stress," should instead say, "electric stress." These occur in and under the subheading, "Typical Dielectric Stress" and under the subheading, "Armour Tapes and Coatings."

Page 12: Under the subhead, "Dissipation-Factor Tip-Up," the lower case delta was misrepresented in the last sentence. It should have said, $\Delta \operatorname{Tan} \delta . "$

Page 13: In the second line, Fig. 3 is attributed to Timperley. The data in Fig. 3 was acquired from tests at Manitoba Hydro and should have appeared on page 12 in the last paragraph, "... where the source of partial discharge is internal voids. (Fig. 3)."

In the fourth paragraph, Fig. 4 was attributed to [28]. Fig. 4 should have appeared later in the paragraph: "Other work has been done using directional couplers [30] installed on the isolated phase bus of high speed, hydrogen-cooled machines. (Fig. 4)."

Fig. 2, which originally appeared on Page 12, and Fig. 3, which was published on page 13, are reproduced below. Scales for two axes were omitted in the original publication.

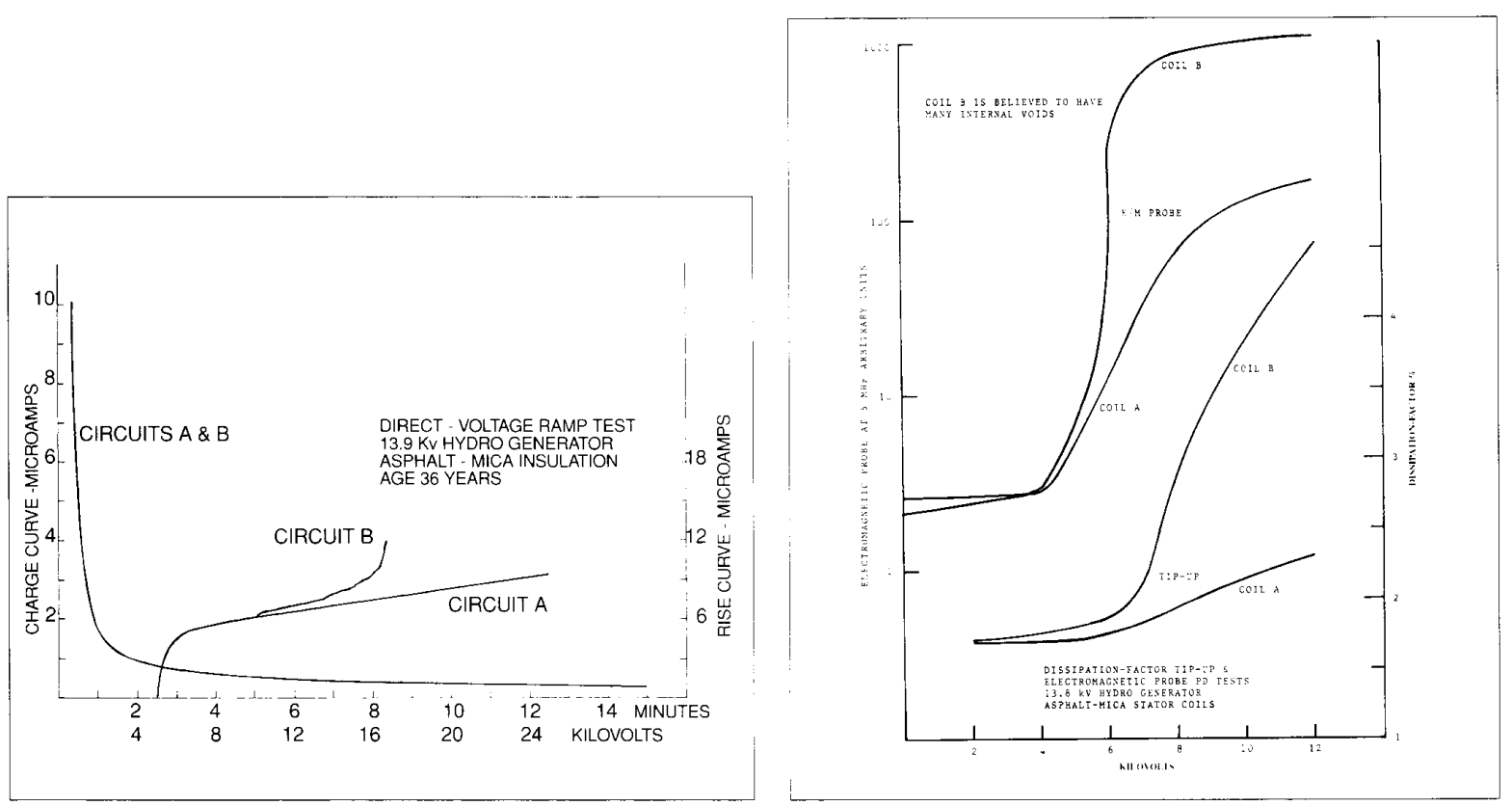

Fig. 2

Fig. 3 


\title{
First Announcement and Call for Papers
}

\section{XVIth International Symposium on Discharges and Electrical Insulation in Vacuum}

\author{
Russia: Moscow and St. Petersburg \\ May 23 - 30, 1994 \\ on board the ship, "Vladimir Mayakovsky"
}

\begin{abstract}
General Information: As the symposium will be held on board a ship, we will have a unique opportunity to sail up the rivers Moskva and Volga as well as on lakes Onega and Ladoga, and finally to the river Neva. We will also pass through several canals, with the opportunity to visit several beautiful ancient Russian towns and famous historical sites. A full-day tour of the St. Petersburg area will be organized, as well. Transportation back to Moscow will be arranged by fast train.

The weather in May in this region of Russia is usually warm during the day, though it may be cool in the evening. Light jackets are recommended.

The symposium will be conducted in English.
\end{abstract}

Address of Local Organizing Committee: Prof. G.A. Mesyats; Institute of Electrophysics, 91 Pervomaiskaya St., GSP-169, Ekaterinburg, 620219 Russia. Phone: (343) 244-0223; Fax: (343) 244-4133; E-Mail: gregory@ami.e-burg.SU

Paper Topics: Vacuum breakdown and pre-breakdown phenomena; vacuum arcs; switching in vacuum; surface flashover; vacuum insulation (including magnetic insulation, accelerators, and others); high current diodes and intense particle beams; discharge in the space environment; emission processes; diagnostic techniques; high power microwaves; commercial applications and opportunities. Nov. 1, 1993, abstracts due; Dec. 15, 1993, notification of paper acceptance; Feb. 1, 1994, submission of camera-ready manuscript.

Submission Procedure: Authors are requested to submit two copies of a 300-word abstract, together with the author's name, address and affiliation, to the representative of ISDEIV94 in the U.S.A.: Tanya Beylin/ISDEIV94, ESRI-USC, 901 Sumter St., Suite 401, Columbia, SC 29208, U.S.A. Telephone/Fax: (803) 254-5490. Feb. 15, 1994-final date for symposium registration.

Fees: $\$ 500$ for food and lodging on boat per attendee; $\$ 250$ registration per scientist.

\section{XVIth International Symposium on Discharges and Electrical Insulation in Vacuum May 23-30, 1994, Moscow and St. Petersburg}

Please send the following information to: ESRI-USC, 901 Sumter St., Suite 401, Columbia, SC, 29208, USA:

Name

Address

Accompanying person/s

Date Signature 